\title{
RESSIGNIFICANDO O COMER: CONSIDERAÇÕES PSICANALÍTICAS SOBRE A OBESIDADE
}

\author{
Manoel da Silva Cavalcante ${ }^{1}$ \\ Allyne Evellyn Freitas Gomes²
}

RESUMO: O presente trabalho visa contribuir com as discussões acerca de como a ressignificação do comer pode facilitar o enfrentamento a obesidade, sob a ótica psicanalítica. Além disso, também possui o interesse de traçar as influências socioculturais que contribuem para esta problemática, quais fatores estão presentes no desenvolvimento de uma relação conflituosa do sujeito com o alimento e quais são as condições psíquicas necessárias para reconstruir esta relação. Utilizando como método uma revisão de literatura narrativa, especialmente de obras apoiadas nas obras de Freud e Lacan. Foram localizados como resultados os múltiplos símbolos que a comida possui, juntamente, a influência da ressignificação do ato de comer como fator positivo na luta contra obesidade.

Palavras-chave: Obesidade. Psicanálise. Comer. Alimentação.

ABSTRACT: The present work aims to contribute to the discussions about how the redefinition of eating can facilitate the confrontation of obesity, from a psychoanalytic perspective. In addition, it is also interested in tracing the sociocultural influences that contribute to this problem, which factors are present in the development of a conflicting relationship between the subject and food and what are the psychic conditions necessary to rebuild this relationship. Using as a method a review of narrative literature, especially works based on the works of Freud and Lacan. As a result, the multiple symbols that food has, together with the influence of the redefinition of the act of eating as a positive factor in the fight against obesity, were found.

Keywords: Obesity. Psychoanalysis. Eat. Food.

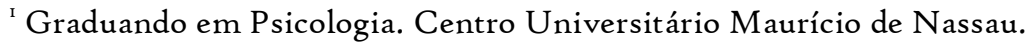

${ }^{2}$ Psicóloga Clínica CRP 02/17920. Mestre em psicologia UFPE, Psicopedagoga. Professora Universitária Uninassau- Suicidiologista em formação em SUICIDOLOGIA: PREVENÇÃO E POSVENÇÃO, PROCESSOS AUTODESTRUTIVOS E LUTO - USCS - Universidade Municipal de São Caetano do Sul. Psicanalista clínica - Atendimentos online e presencial. Professora universitária Avaliadora no comitê de iniciação científica do centro universitário Uninassau do grupo SER Educacional. Pesquisadora em projetos de iniciação cientifica - Psicossomática e Luto. Orientadora de trabalhos de conclusão de curso. Pós graduanda em: Desing instrucional,. Desenvolve pesquisas no âmbito da saúde e ações de extensão e pesquisa em saúde e educação. Com ênfase em Psicanálise, psicossomática, luto, suicídio e EAD. E-mail: allyne.evellyn@gmail.com
} 


\section{INTRODUÇÃO}

Durante uma breve experiência como facilitador de um grupo terapêutico de enfrentamento a obesidade, organizado por uma rede de saúde privada, pude acompanhar pacientes que buscavam a cirurgia bariátrica. Durante o processo eram submetidos a dietas restritivas que, na imensa maioria das vezes, não eram levadas adiante pelo indivíduo. Junto a isso, também recebiam acompanhamentos de médicos endocrinologistas, que na maioria das vezes também, não atestavam alterações orgânicas que resultassem diretamente no quadro de obesidade.

Em consonância, é bastante comum encontrar pessoas que durante toda a sua vida nunca se questionaram sobre seus hábitos alimentares. Tais como: quais alimentos e situações mobilizam seu apetite, como o seu comportamento alimentar foi desenvolvido e quais influências socioculturais estão presentes neste processo. De fato, essas questões não costumam estar presentes nos debates do senso comum e são poucas as situações onde a grande mídia busca abordar este tema. Além disso, os aspectos psíquicos envolvidos no enfrentamento a obesidade possuem um enfoque menor em comparação com os principais tratamentos, tais como: dietas, atividade física e utilização de fármacos. Aliado a grande

mídia, estas indústrias alcançam lugar de protagonismo no processo de emagrecimento, tendo por objetivo maior o lucro explorando as fraquezas do indivíduo obeso.

Nesse sentido, os fatores psicológicos, tais como: ansiedade, depressão e emoções negativas também se manifestam na relação do sujeito com os alimentos, por isso, a perspectiva psicológica do indivíduo não deve ser desconsiderada no processo de enfrentamento à obesidade. Em vista disso, se torna interessante entender qual o significado do alimento para o indivíduo obeso e como a mudança deste sentido pode se tornar um aliado no enfrentamento da obesidade.

Junto a isso, também se denota o fato dessa área ser pouco explorada nos cursos de graduação em psicologia, por isso, é relevante nos apropriarmos mais desse debate e pesar os benefícios da aplicação psicológicas e psicanalíticas no comportamento alimentar das pessoas com obesidade. Por conseguinte, refletir quais seriam os desdobramentos na saúde mental dos indivíduos e as novas configurações de sentido no ato de comer. 
Simultaneamente, observa-se, na cultura e sociedade, uma crescente busca por um corpo perfeito e o surgimento de diversos procedimentos e dietas duvidosas para a saúde física e, principalmente, mental. Denota a urgência da construção de conhecimentos psíquicos que possam dar uma resposta à sociedade. Para que possa se tornar uma referência confiável neste processo, sendo oposição aos movimentos que querem ocupar este local, todavia, sem compromisso com a saúde mental dos indivíduos.

Neste âmbito, o trabalho também possui o interesse de aproximar a psicanálise e a psicologia deste debate tão atual e urgente. Através da revisão bibliográfica de obras que construíram pontes até a compreensão atual sobre o comer e o corpo obeso, dentro do ponto de vista psicanalítico. Principalmente utilizando obras que se apoiam nas obras dos teóricos Freud e Lacan. Juntamente, compreender sob a luz da psicanálise, possíveis razões que podem desenvolver no sujeito uma relação conflituosa com a comida. Ao mesmo tempo, avaliar quais são as condições psíquicas capazes de reconstruir a relação do indivíduo com o alimento.

\section{MÉTODO}

Esta pesquisa configura-se como qualitativa e a abordagem metodológica utilizada foi a revisão narrativa de literatura. Com a pesquisa realizada através de bases cientificas de dados como a Pepsic, Scielo e Google Scholar. Os dados a serem coletados serão em língua portuguesa e publicados entre o período de 1999 à 2020. Pesquisados a partir das seguintes palavras chaves: obesidade, psicanálise, comer compulsivo e comportamento alimentar. Juntamente, o trabalho terá como enfoque a abordagem psicanalítica e contará, especialmente, com a revisão de literaturas apoiadas nas obras de Freud e Lacan.

Foram pesquisados 30 artigos a partir dos termos citados acima, dentre esses, apenas os que traziam discussões mais aprofundadas sobre o entendimento do comer através $\mathrm{da}$ psicanálise e psicossomática seguiram adiante na construção deste trabalho. Foram descartadas as obras que traziam poucas elaborações subjetivas referentes a temática 


\section{RESULTADO E DISCUSSÃO}

Nos últimos anos estamos acompanhando um crescente aumento da obesidade entre a população brasileira, o percentual de adultos obesos no país mais do que dobrou em 17 anos, indo de 12,2\%, entre 2002 e 2003, para 26,8\%, em 2019 (IBGE, 202I). A partir deste dado, podemos começar a explorar esta questão desde o nosso primeiro contato com o alimento, que se dá através do leite materno durante os primeiros meses de vida do bebê. De acordo com Nasio (1999), também existe outro aspecto de prazer envolvido neste ato, do ponto de vista psicanalítico, a sucção e o mordiscar logo se tornam a satisfação buscada, fora da necessidade natural. É relevante também citar que a boca é uma região erógena capaz de proporcionar prazer.

Em consonância, é comum associar o alimento com esse momento de cuidado e carinho da relação materna, tendo em vista que o alimento é a própria mãe. Segundo Kirch (2017), quando o leite e o seio materno são retirados da criança, ela se depara com a falta, se isso não for trabalhado positivamente, o indivíduo tentará encontrar outro objeto substitutivo para este objeto de desejo. Assim o sujeito começa a busca por representante desse momento

materno. Ainda conforme Kirch (2017), a alimentação possui uma construção afetiva e de carinho, pois é através da boca que conhecemos o mundo. Essa mensagem de bem estar associada à alimentação está registrada em nosso inconsciente como algo que nos ampara.

O comer é atribuído de sentidos, dentre estes, muitos podem ser conhecidos do sujeito. Sendo assim, repensar o comer se mostra uma dinâmica relevante. Entre as modalidades psíquicas fundamentais, é possível dar ênfase aos processos regressivos, principalmente as chamadas regressões parciais (DEJOURS, 2014). Haja vista que também é possível que o alimento se torne um símbolo de um movimento regressivo a segurança e satisfação vivenciada na infância, tendo por objetivo o alivio de sentimentos que causam desprazer, tais como a ansiedade. Estes são fatores que interferem no desenvolvimento de uma relação positiva entre o sujeito e a comida.

Além disso, não é possível pensar o sujeito e seu hábito alimentar sem considerar o contexto social em que se desenvolve (SEIXAS et al., 2020), os fatores socioculturais, socioeconômicos e demográficos influenciam na alimentação dos indivíduos. Estas 
circunstâncias refletem no estilo de vida do sujeito, no comer e na construção da sua relação com a comida, como resultado, maior a chance de um corpo obeso como consequência. Ademais, os alimentos sempre foram utilizados, em diferentes culturas e sociedades, como forma de celebração. Estes valores culturais tendem a perpetuar a associação entre alegria e o comer (BALAIAS, 2009).

Logo percebemos que o comer é repleto de sentidos, e estes sentidos tanto podem ser positivos, quanto negativos na relação do sujeito com a comida. A relação do sujeito com a comida pode ser considerada negativa, quando o comer passa a ser disfuncional e causar sofrimento. No entanto, neste processo também não é possível desconsiderar os fatores sociais e culturais que colaboram com a angústia do indivíduo com obesidade. Conforme Fônseca (2010), no século XIX compreendia-se a obesidade como consequência de problemas morais, psíquicos e de autoestima. O obeso passou a ser visto como uma pessoa de restrições intelectuais, com mau funcionamento mental, covarde e egoísta.

Ademais, mesmo não sendo o objetivo deste trabalho explanar sobre este ponto, ainda se soma ao processo de obesidade os fatores fisiológicos, tais como: reações endógenas e o processamento de gorduras e açúcares no corpo. Sendo fundamentais também no enfrentamento da obesidade, os supracitados processos tradicionais de emagrecimento. Rapidamente percebemos que a obesidade se trata de um processo biopsicossocial e que o significado do comer também possui influência no processo de enfrentamento à obesidade.

Segundo Marques (2008), o fato de a obesidade estar determinada na sociedade como uma doença unicamente do corpo, por sua vez, não facilita que o obeso construa um questionamento acerca da sua obesidade, o que dificulta a subjetivação dos seus sofrimentos referidos ao corpo (apud FÔNSECA, 2010). Desconsiderando o fator psíquico presente na fome e no comer, criam-se eventuais confusões no pensamento do sujeito obeso, que passa a não entender seu desejo pela comida que se estende para além da necessidade física.

Neste ponto, em questão, é possível afirmar que a fome do obeso é pulsional. A pulsão é o instinto que se desnaturaliza, que se desvia de suas fontes e objetos específicos. A fonte da pulsão é o instinto, mas não se reduz a ele (GARCIA-ROZA, 2009). O conceito de pulsão postulado pela psicanálise pode explicar didaticamente o que mobiliza a fome do indivíduo com obesidade. De acordo com Freud (2013), uma pulsão nos aparecerá como sendo um 
conceito situado na fronteira entre o psíquico e somático, como representante psíquico dos estímulos originados do organismo e que alcançam a mente.

O sujeito obeso desloca e envolve sua pulsão no comer e, partir daí, encontra no alimento um substitutivo capaz de satisfazer parcialmente seu desejo. Conforme Garcia-Roza (2009), o objeto da pulsão é um meio para o atingimento do objetivo que é a satisfação. Este objeto pode ser uma pessoa ou parte dela, pode ser real ou fantasmático. Todavia, essa dinâmica torna o comer do sujeito disfuncional, o fazendo comer além do que necessita, desenvolvendo potenciais malefícios físicos e mentais.

Não obstante, haja vista o imediatismo que permeia a sociedade, cotidianamente observamos novas soluções mágicas para perder peso num curto intervalo de tempo. Encontramos desde dietas absurdas sem base cientifica ou recomendação médica, até procedimentos estéticos e cirurgias onde o sujeito precisará dispor de grande poder aquisitivo para realizá-las. Pondo, além de tudo, sua vida em risco. Em paralelo, a sociedade exige ainda mais perfeição dos corpos, associando a beleza física a qualidades morais e sociais, considerando os preconceitos que corpo obeso carrega. Por exemplo: o estigma de que o obeso é preguiçoso, desleixado, etc.

De fato, não há solução mágica, mesmo compreendendo todas as limitantes no processo de emagrecimento, é necessário que o indivíduo obeso decida conscientemente pela alternativa proposta por médicos, nutricionistas, educadores físicos e psicólogos no enfrentamento da obesidade.

Para isso, segundo Fônseca (2010), é necessário que o obeso se interrogue acerca da sua obesidade, e que assim tenham a possibilidade de reconhecer que há algo por trás desse comer não saciável. Só repensar o comer não soluciona o problema, tampouco, sem tal questionamento, dificilmente o sujeito conseguirá mudanças significativas. Sendo este movimento o primeiro passo para que o indivíduo desenvolva condições de reconstruir os fatores psíquicos desenvolvidos durante toda sua vida em relação ao seu comer.

De acordo com Reis e Godinho (2018), o corpo é autobiográfico no que diz respeito a sua compreensão como um todo. Também é transdisciplinar, subjetivo e dotado de complexidades biológicas e psicológicas. Apesar da dicotomia didática sobre o corpo e a mente, cabe refletir que esta divisão prática não existe, sendo a mente parte integrante do 
corpo. A mente é capaz de afetar e ser afetada pela integralidade do homem, que não deve ser visto como partes isoladas.

Coube a Freud o pioneirismo de assinalar que nem toda comunicação é unicamente verbal, e que, de alguma forma, o corpo também comunica, tal como se pode depreender desta frase, a propósito do "Caso Dora" (1905): "nenhum mortal pode guardar um segredo; se sua boca permanece em silêncio, falarão as pontas de seus dedos [...]"." (ZIMERMAN, 2008, p. 327).

Dentro desta lógica, para além da própria construção do sentido que o sujeito atribui ao comer, também pode-se considerar que o próprio corpo obeso pode ser uma manifestação inconsciente daquilo que ele quer comunicar. A psicologia nomeia este movimento como psicossomático. Neste caso, então, a comida se configura como um meio de linguagem na qual o sujeito utiliza para comunicar em seu próprio corpo aquilo que psiquicamente não consegue simbolizar. A literatura demonstra que a somatização como resposta à dor mental é uma resposta psíquica comum do homem. A reciproca também acontece, já que o corpo adoecido desencadeia fortes impactos sobre a mente (ZIMERMAN, 2008).

Aliado a isso, é comum que durante o processo de emagrecimento, que a estrutura psíquica do indivíduo possa vir se sentir ameaçada. Trazendo uma certa resistência em abrir mão do prazer que o inconsciente encontrou como forma de satisfação. Logicamente, tanto os fatores físicos e sociais também possuem influência neste processo.

Portanto, a mente se manifesta do início ao fim dentro do processo da obesidade, sem a ressignificação do comer e sem o desenvolvimento de ferramentas psíquicas, a cura para a obesidade se mostra ainda mais difícil de atingir e assegurar. Embora a medicina moderna busque a objetividade na deteç̧ão das doenças, a investigação de fatores subjetivos se faz fundamental para uma cura real (REIS, GODINHO, 2018).

Nesta lógica, para criar condições psíquicas capazes de reconstruir o sentido do alimento para o sujeito, se torna imprescindível que o indivíduo obeso seja capaz de construir reflexões sobre o que sua fome e seu corpo estão tentando comunicar. Por conseguinte, podemos destacar a relevância do processo clínico psicanalítico como capaz de contribuir neste processo. Conforme Zimerman (2008), cabe ao terapeuta incentivar o paciente à verbalização de fantasias, desejos e afetos, assim como realizar a análise das funções do ego consciente e estabelecer um vínculo entre o consciente e o inconsciente. 


\section{CONSIDERAÇÕES FINAIS}

É relevante informar que este trabalho não possui o interesse de culpabilizar o sujeito por seu sofrimento. Existem múltiplos fatores que estão presente na obesidade, a julgar por ser uma problemática que precisa ser abordada de maneira interdisciplinar. Cabendo a cada área do conhecimento contribuir para a construção de estratégias que promovam melhor qualidade de vida e saúde do indivíduo obeso. Entretanto, a psicanálise deve se posicionar diante deste cenário e utilizar seu rico arcabouço teórico na melhoria da qualidade do debate que é realizado atualmente.

Outrossim, também é importante que exista melhor entendimento do procedimento da cirurgia bariátrica, considerando que em muitos casos é essencial para a rápida manutenção da saúde do paciente obeso. No entanto, o que deve ser questionado é a utilização desse recurso como método ágil para alcance de um desejo estético. Além disso, a psicologia precisa intermediar este processo entre o desejo do paciente e sua realidade psíquica. Tendo em vista que o sujeito é multifacetado e que não só seu corpo deve fazer parte do enfrentamento à obesidade, como também sua mente.

Contudo, ainda existem muitos aspectos que não foram abordados neste trabalho,

assim sendo, este estudo está disponível a participação de novas ideias que possam aproximar a psicanálise e a psicologia para dentro deste debate. Sendo necessário também que esta área esteja presente dentro dos cursos de graduação em psicologia e psicanálise.

\section{REFERENNCIAS}

BALAIAS, Diana. Quando as emoções comandam a fome. Peritia: Revista Portuguesa de Psicologia, [S. L.], p. I-4, I5 dez. 2009.

DEJOURS, C. O corpo da Psicossomática. Psicologia Revista, [S. l.], v. I4, n. 2, p. 245-256, 2014. Disponível em: https://revistas.pucsp.br/index.php/psicorevista/article/view/ı8ıз. Acesso em: 24 nov. 2021.

FARAH, Juliana Ferreira Santos; CASTANHO, Pablo. Dimensões psíquicas do emagrecimento: por uma compreensão psicanalítica da compulsão alimentar. Revista 
Latinoamericana de Psicopatologia Fundamental, [S.L.], v. 2I, n. I, p. 4I-57, jan. 2018. FapUNIFESP (SciELO). http://dx.doi.org/ro.1590/1415- 4714.2018v2InIp41.4.

FÔNSECA, Priscilla Caroline Alvim. Obesidade como sintoma: Algumas considerações sob ótica da psicanálise. 2010. I5 f. TCC (Graduação) - Curso de Psicologia, Centro Universitário Jorge Amado, Salvador, 2oro. Disponível em: https://www.psicologia.pt/artigos/textos/TLor64.pdf. Acesso em: I5 fev. 2021

FREUD, Sigmund. As Pulsões e Seus Destinos: volume 2 de obras incompletas de Sigmund Freud. [S.L]: Autêntica, 2013.

GARCIA-ROZA, Luiz Alfredo. Freud e o Inconsciente. 24. ed. Rio de Janeiro: Zahar, 2009. $236 \mathrm{p}$.

IBGE - INSTITUTO BRASILEIRO DE GEOGRAFIA E ESTATÍSTICA. Um em cada quatro adultos estava obeso em 2019. Brasil: IBGE, 2021. Disponível em: https://censo202I.ibge.gov.br/2012-agencia-de-noticias/noticias/29204-um-em-cada quatro adultos-do-pais-estava-obeso-em

2019.html\#: :text=O\%2opercentual\%2ode\%2opessoas\%20obesas,quase\%2odois\% 20ter\% 3 3\% A7os\%2odos\%2obrasileiros . Acesso em: 30 mar. 2021.

KIRCH, Jéssica da Rosa. Obesidade, causas e o tratamento à luz da psicanálise. 2017. $38 \mathrm{f}$. TCC (Graduação) - Curso de Psicologia, Universidade Regional do Noroeste do Estado do Rio Grande do Sul- Unijuí, Ijuí, 2017. Disponível em: https://bibliodigital.unijui.edu.br:8443/xmlui/bitstream/handle/123456789/4856/Jessica\%2od a\%20Rosa\%2oKirch.pdf?sequence= $\mathrm{I} \&$ is Allowed $=\mathrm{y}$. Acesso em: o8 maio 2021.

NASIO, J.D. O prazer de ler Freud, Rio de Janeiro: Jorge Zahar Ed., I999.

REIS, Kelly Specht dos; GODINHO, Lucia Belina Rech. PSICOSSOMÁTICA: UMA VISÃO HOLÍSTICA DO HOMEM. Cippus: Revista de Iniciação Científica, Canoas, v. 6, p. $\quad$ I-I4, 20I8. Disponível em: https://revistas.unilasalle.edu.br/index.php/Cippus/article/view/3977/pdf. Acesso em: 22 nov. 2021.

SEIXAS, Cristiane Marques et al. Fábrica da nutrição neoliberal: elementos para uma discussão sobre as novas abordagens comportamentais. Physis: Revista de Saúde Coletiva, 
[S.L.], v. 30, n. 4, p. I-2I, 2020. FapUNIFESP (SciELO). http://dx.doi.org/ro.159o/soio3733120203004II.

ZIMERMAN, D. E. Manual da Técnica Psicanalítica, uma re-visão. Porto Alegre: Artmed, 2008. 